\title{
Aortic root reconstruction through valve-sparing operation: critical analysis of 11 years of follow-up
}

\author{
Análise crítica da reconstrução da raiz da aorta com a preservação da valva aórtica: 11 anos de seguimento
}

Ricardo Ribeiro DIAS ${ }^{1}$, Omar V. MEJIA², Edemir V. CARVALHO JR ${ }^{3}$, Diogo O. C. LAGE ${ }^{3}$, Altamiro Ribeiro DIAS $^{4}$, Pablo M. A. POMERANTZEFF ${ }^{5}$, Charles MADY ${ }^{6}$, Noedir A. G. STOLF ${ }^{7}$

\begin{abstract}
Introduction: The use of valved conduit is the standardized operation for aortic root replacement. The aim of this study is to assess the valve-sparing ascending aortic root reconstruction.

Methods: From 1996 to 2008, 54 consecutive patients underwent two different techniques of valve-sparing aortic root operation (40 Yacoub operations and 14 David operations). Mean age was $48 \pm 14$ years (range 17 to 74 ). $66.7 \%$ were male and $29.6 \%$ experienced Marfan's syndrome. The mean Euroscore was $4 \pm 1.25$. The mean follow- up time was 4.1 years (from 49 days to 10.9 years). Clinical and echocardiographic parameters were assessed. T-Student paired test, McNemar Non Parametric test and the KaplanMeyer Survival Curves have been used.

Results: The hospital mortality was $5.6 \%$ and the average hospitalization time was $9 \pm 4$ days. One non-related late
\end{abstract}

death (2\%) was reported. The actuarial survival and freedom from reoperation were respectively $94.4 \%$ and $96 \%$ within 11 years of follow-up. There were improvement in functional class $(P=0.002 ; 78 \%$ FC I $)$, in reduction of aortic insufficiency $(P<0.001 ; 78 \%$ with or without discrete reflux), in reduction of systolic and diastolic diameters, left ventricular end systolic and diastolic volumes (respectively $P=0.004$; $P<0.0001 ; P=0.036$ and $P<0.001)$. Two $(3.9 \%)$ patients required aortic valve replacement with 4 and 10 years from the surgery. No thromboembolic, endocarditis or bleeding events were reported during the follow-up.

Conclusion: The valve-sparing operation for aortic root aneurysms is an effective alternative to the use of a valved conduit.

Descriptors: Aortic aneurysm, thoracic/surgery. Aortic valve. Aorta/surgery.
1. PhD in Medicine at Cardiovascular Surgery Department of the Heart Institute of the Faculty of Medicine, University of São Paulo. Assistant Physician of the Surgical Unit of General Heart Diseases of the Heart Institute of the Faculty of Medicine, University of São Paulo.

2. Residence in Cardiovascular Surgery at Heart Institute of the Faculty of Medicine, University of São Paulo; Postgraduate Student of the Cardiovascular Surgery Department of the Heart Institute of the Faculty of Medicine, University of São Paulo.

3. Surgery Resident at Heart Institute of the Faculty of Medicine, University of São Paulo.

4. Full Professor at Cardiovascular Surgery Department of the Heart Institute of the Faculty of Medicine, University of São Paulo; Director of the Homograft Laboratory at Surgical Unit of the Heart Institute of the Faculty of Medicine, University of São Paulo.

5. Full Professor at Cardiovascular Surgery Department of the Heart Institute of the Faculty of Medicine, University of São Paulo; Director of the Surgical Unit of Valve Diseases of the Heart Institute of the Faculty of Medicine, University of São Paulo.
6. Full Professor of the Cardiology Department of the Heart Institute of the Faculty of Medicine, University of São Paulo; Director of the Clinical Unit of Myocardiopathies of the Heart Institute of the Faculty of Medicine, University of São Paulo.

7. Titular Professor of Cardiovascular Surgery of the Heart Institute of the Faculty of Medicine, University of São Paulo; General Director of the Heart Institute of the Faculty of Medicine, University of São Paulo.

This study was carried out at Heart Institute of the Faculty of Medicine of the University of São Paulo, São Paulo, SP, Brazil.

\section{Correspondence address:}

Ricardo Ribeiro Dias

Av. Dr. Enéas de Carvalho Aguiar, 44 - Cerqueira César - São Paulo, SP, Brasil - CEP: 05403-000.

E-mail: ricardo.dias@incor.usp.br

Article received on October $13^{\text {th }}, 2009$ Article accepted on February 14th 2010 


\section{Resumo}

Introdução: A utilização do tubo valvulado é a operação clássica para a reconstrução da raiz da aorta. O objetivo deste trabalho é avaliar a reconstrução da aorta ascendente com a preservação da valva aórtica.

Métodos: Entre 1996 e 2008, 54 pacientes consecutivos (66,7\% do sexo masculino), com idade média de $48 \pm 14$ anos, foram submetidos à reconstrução da aorta ascendente e preservação da valva aórtica (40 remodelamentos e 14 reimplantes). O Euroscore médio foi de $4 \pm 1,25$ e $29,6 \%$ eram portadores de síndrome de Marfan. $O$ tempo médio de seguimento foi de 4,1 anos (49 dias até 10,9 anos). Foram avaliados por parâmetros clínicos e ecocardiográficos. Para a análise dos dados foram utilizados os testes $t$ de Student pareado, o não-paramétrico de McNemar e a curva de sobrevida de Kaplan-Meyer.

Resultados: A mortalidade hospitalar foi de 5,6\%. O tempo médio de internação foi de $9 \pm 4$ dias. Houve um óbito tardio

\section{INTRODUCTION}

Regardless of the etiology in surgeries of aneurysms involving the aortic root, the preservation of the aortic valve happened only in $1.7 \%$ of the cases, while the mitral repair procedures were much more frequent (46.5\%) [1]. The standard operation to treat the aortic root diseases is the mechanical valve conduit replacement ("Bentall" procedure). This procedure represents a low risk, reproductive and longevity surgical option. However, thromboembolic and/or bleeding complications related to sustained anticoagulation are the problem [2,3]. On the other hand, when the biological composite graft is used, the need for reoperation is also an issue because of the valve degeneration.

The aortic valve-sparing operations are interesting alternative techniques aiming at improving longevity free from mechanical - or biological - valve-related complications. Two procedures were described for this purpose: the remodeling technique proposed by Yacoub [4], with the excision of the coronary ostia and resection of aortic sinuses up to a rim of 2 to $3 \mathrm{~mm}$ of aortic wall (and complete resection of the aortic root) sutured with Dacron tubular graft trimmed to produce tongue-shaped extensions, thus creating three new Valsalva sinuses (Figure 1). Alternatively, David and Feindel [5] proposed the reimplantation technique, in which the main difference from the procedure described above is related to the inside graft fixation of the commissural pillars and aortic ring (Figure 2). não relacionado $(2 \%)$. A sobrevida e sobrevida livre de reoperação nos 11 anos de seguimento foram respectivamente de $94,4 \%$ e $96 \%$. Houve melhora da classe funcional $(P=0,002)(78 \% C F$ I), redução da insuficiência aórtica $(P<0,001)(78 \%$ sem ou com refluxo discreto), redução dos diâmetros sistólico e diastólico, dos volumes sistólico final e diastólico final do ventrículo esquerdo, respectivamente $P=0,004 ; P<0,001 ; P=0,036$ e $P<0,001$. Dois pacientes foram submetidos à troca de valva aórtica $(3,9 \%)$ com 4 e 10 anos da operação. Não foram observados fenômenos tromboembólicos, hemorrágicos ou endocardite durante o seguimento.

Conclusão: A reconstrução da raiz da aorta com a preservação da valva aórtica é uma alternativa eficaz ao uso do tubo valvulado.

Descritores: Aneurisma da aorta torácica/cirurgia. Valva aórtica. Aorta/cirurgia.

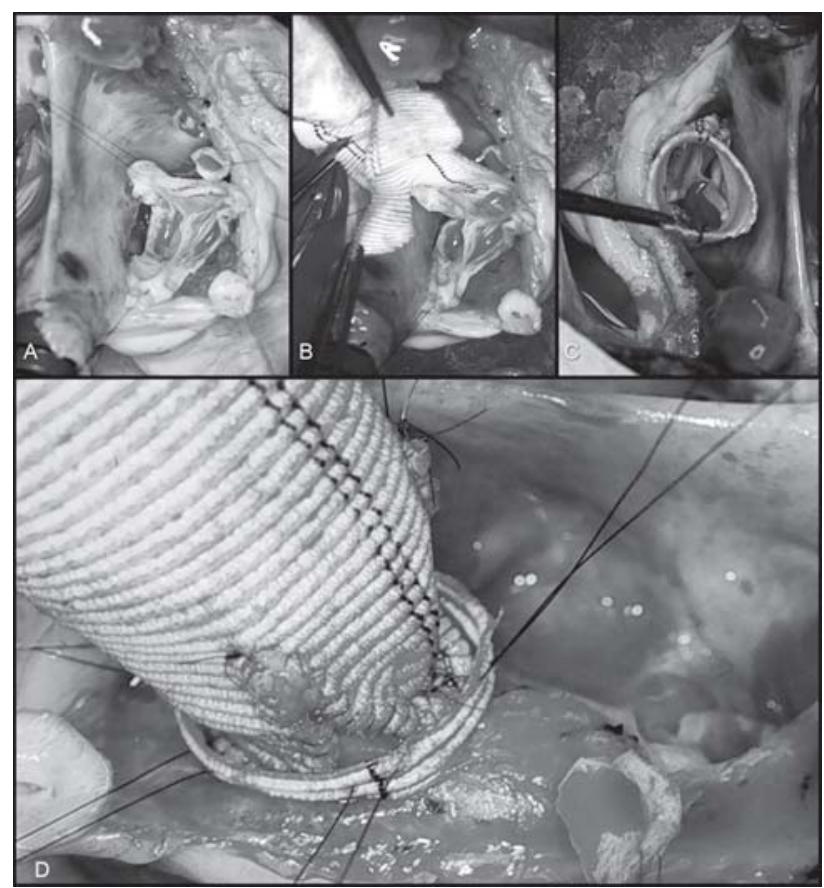

Fig. 1 - Intraoperative images: A. The sinuses of Valsalva and the ascending aorta were excised, leaving a $4 \mathrm{~mm}$ rim attached to the aortic annulus, and both coronary ostia. B. A vascular Dacron graft was trimmed to produce tongue-shaped extensions for replacement of the excised sinuses. C. These tongues were sutured to the aortic annulus; the coronary ostia were reimplanted into the graft using the "button" technique. D. External fixation of the aortic ring with a Dacron strap as a procedure complementation to the classic technique proposed by Yacoub 


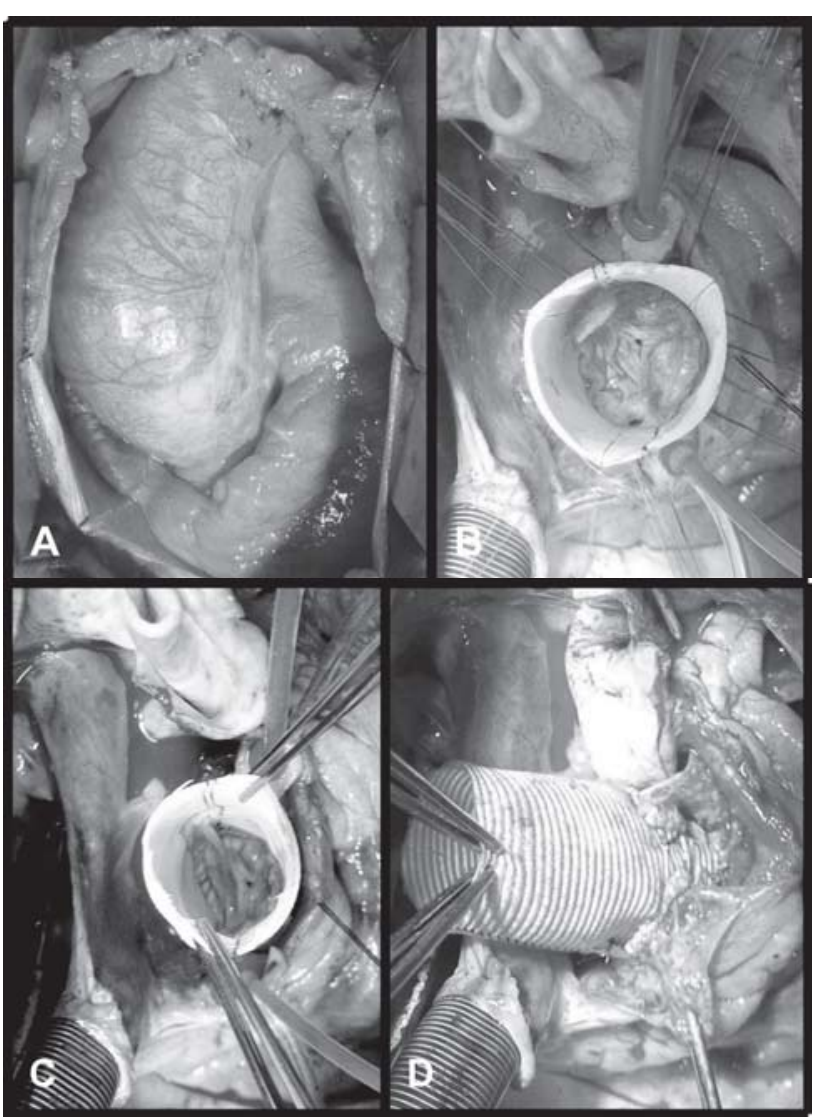

Fig. 2 - Intraoperative images. A. The ascending aortic aneurysm. $B$. The graft fixed in the left ventricular outflow tract. C. Fixation of commissural pillars and aortic ring in the graft, offering an external sustentation to this structure. D. Reimplantation of the coronary ostia in the graft using the "button" technique, illustrating the final aspect of this surgery

However, there may still be problems to be addressed. Even if in the remodeling technique a more physiological reconstruction of the aortic root occurs, the dilation of the aortic ring may be a problem, unless some kind of external ring fixation is performed (Figure 1D). In the reimplantation technique, despite the variations proposed, the possibility of non reconstruction of the Valsalva sinuses may result in a change of the hydrodynamic properties of the coronary flows and a late structural failure of valve leaflets due to traumatisms within the tubular graft [6,7]. In spite of the low reproducibility and the more demanding technical efforts to use it regularly, the valve-sparing techniques can be applicable and reports show 10-year plus follow-up patients presenting very low complications rates [8-10].

Both the Yacoub remodeling and the David reimplantation valve-preserving aortic root reconstructions were initiated in our Institution in 1996 and 2001 respectively. This study aims at evaluating the long-term results of the aortic root reconstruction through the aortic valve-sparing operations.

\section{METHODS}

A retrospective review of our database, clinical and echocardiography data from chart review and phone interview, and an invitation to do a 2008 echocardiogram if none had been done in the respective year were all used in order to collect relevant information.

Between January 1996 and July 2008, 54 consecutive patients with aortic root disease underwent an aortic valvesparing operation (associated procedures in 11.1\%). The remodeling or reimplantation valve-sparing aortic root reconstructions were chosen at surgeon's discretion, of which $74 \%$ were remodeling and $26 \%$ reimplantation.

Patients' demographics and intraoperative data are shown in Table 1.

Table 1. Demographics and intraoperative data of patients undergoing aortic valve-sparing and additional surgical procedures.

\begin{tabular}{|c|c|c|}
\hline Characteristics & $\mathrm{n}$ & $\%$ \\
\hline Number of patients & 54 & \\
\hline \multicolumn{3}{|l|}{ Sex } \\
\hline Male & 36 & 66.7 \\
\hline Female & 18 & 33.3 \\
\hline Age & $48 \pm 14$ (17 to 74$)$ & \\
\hline \multicolumn{3}{|l|}{ NYHA } \\
\hline FC I & 6 & 11.1 \\
\hline FC II & 29 & 53.7 \\
\hline FC III & 16 & 29.6 \\
\hline FC IV & 3 & 5.5 \\
\hline \multicolumn{3}{|l|}{ Aortic regurgitation } \\
\hline I - II & 20 & 37 \\
\hline III & 15 & 28 \\
\hline IV & 19 & 35 \\
\hline Ascending/Root aneurysm & 49 & 90.7 \\
\hline Acute dissection & 5 & 9.3 \\
\hline Mean aortic diameter (mm) & $56 \pm 5.3$ & \\
\hline Marfan’s syndrome & 16 & 29.6 \\
\hline Tricuspid valve & 1 & 0.5 \\
\hline EuroSCORE & $4 \pm 1.25$ (3 to 8 ) & \\
\hline \multicolumn{3}{|l|}{ Surgical techniques } \\
\hline Remodeling & 40 & 74.1 \\
\hline Reimplantation & 14 & 25.9 \\
\hline ECC (min) & $65.7 \pm 32.5$ & \\
\hline X-Clamp (min) & $35.9 \pm 24.2$ & \\
\hline \multicolumn{3}{|l|}{ Additional procedures } \\
\hline CABG & 3 & 5.5 \\
\hline Mitral valve treatment & 2 & 3.7 \\
\hline Subaortic ring resection & 1 & 0.5 \\
\hline
\end{tabular}


Coronary angiography, transthoracic echocardiogram, and computed tomography scans or magnetic resonance images were performed routinely in elective cases. If the transesophageal echocardiogram and computed tomography showed an acute aortic dissection, surgery was initiated with no further diagnostic procedures. The decision to preserve the aortic valve was made always intraoperatively by the surgeon after inspection of the leaflets and the root geometry (whenever the regurgitation was associated to annular dilatation and it was possible to restore valve competency).

The average follow-up time was $51.4 \pm 36.5$ months ( 0 133 months). Clinical information was obtained from the chart records or by phone interview with $96 \%$ of patients. Complications such as endocarditis, pulmonary or systemic thromboembolism or bleeding were registered following the recommendations of the American Association for Thoracic Surgery and the Society of Thoracic Surgery [11].

Postoperative echocardiogram evaluations from 2008 were completed in $88 \%$ of patients.

Table 2. Comparative analyses of echocardiographic measurements in the preoperative period and the current status of patients submitted to the valve-sparing surgery.

\begin{tabular}{lccccc}
\hline Variable & Echo & $\mathrm{n}$ & Mean & sd & $P^{*}$ \\
\hline EF & Pre op & 52 & 0,65 & 0,11 & \\
& Current & 52 & 0,61 & 0,09 & \\
LVEDD (mm) & Pre op & 52 & 61,88 & 10,00 & $<0,001$ \\
& Current & 52 & 56,87 & 9,84 & \\
& & & & & \\
LVESD (mm) & Pre op & 52 & 41,46 & 10,08 & 0,004 \\
& Current & 52 & 37,79 & 7,79 & \\
& & & & & \\
LVEDV (ml) & Pre op & 52 & 229,38 & 110,64 & $<0,001$ \\
& Current & 52 & 181,40 & 88,25 & \\
& & & & & \\
LVESV (ml) & Pre op & 52 & 93,62 & 84,24 & 0,036 \\
& Current & 52 & 72,83 & 42,63 & \\
\hline
\end{tabular}

(*) Paired t Student test probability description level

$E F$ : ejection fraction; LVEDD: left ventricular end-diastolic diameter; LVESD: left ventricular end-systolic diameter; LVESV: left ventricular end-systolic volume

Continuous variables are expressed as mean $\pm \mathrm{SD}$. Both the paired t-Student and the McNemar Non Parametric tests were used in the analysis of quantitative and qualitative variables, respectively. The Kaplan-Meyer Outcome Curves were used for the evaluation of time-related variables. A $P$ value $\leq 0.05$ was considered significant. All data analyses were performed with SPSS 13 for Windows (SPSS Inc.).

\section{RESULTS}

In-hospital and 30-day mortality was 5.6\% (3/54). The early mortality was caused by multiple organs failure in 1 patient, acute heart failure in 1 patient and intraoperative bleeding in 1 patient. The average of hospital stay time was $9 \pm 4$ days.

The late mortality was $1.9 \%$ related to pancreas cancer.

The actuarial survival was $94.4 \%$ within 11 years (Figure 3).

Two (4\%) patients required reoperation for significant aortic regurgitation within 4 and 10 years. One had Marfan's syndrome, both had preoperative severe aortic regurgitation due to aortic annulus dilatation, and underwent remodeling valve-sparing aortic root reconstruction. The actuarial freedom from reoperation due to incompetence of the reconstructed aortic valve was $96 \%$ (Figure 4). There was no mortality in reoperation for implantation of a mechanical valve. Neither thromboembolic, nor bleeding, nor endocarditis events were observed.

There was significant improvement of patients' functional class for heart failure with $80 \%$ of the patients in functional class I (Figure 5).

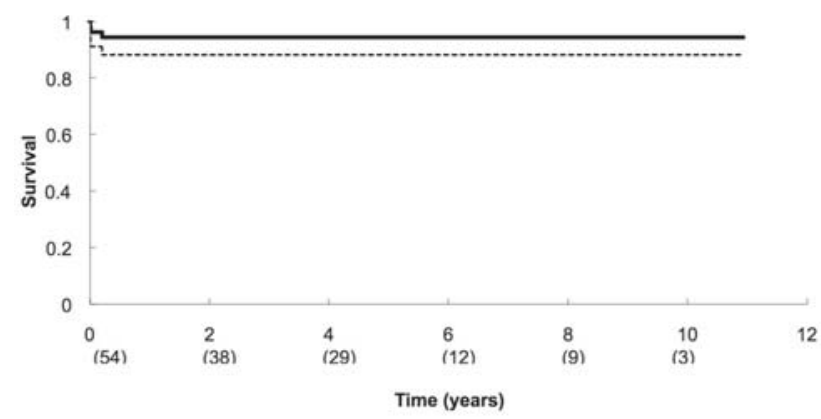

Fig. 3 - Late survival after aortic valve-sparing operation (94.4\% within 11 years)

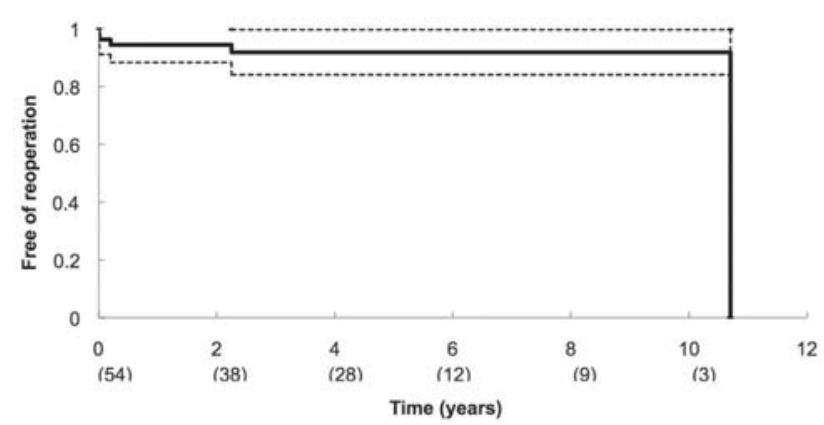

Fig. 4 - Actuarial freedom from reoperation of the reconstructed aortic root (as the patient with longer follow-up time needed to replace the aortic valve, the curve falls to zero) 


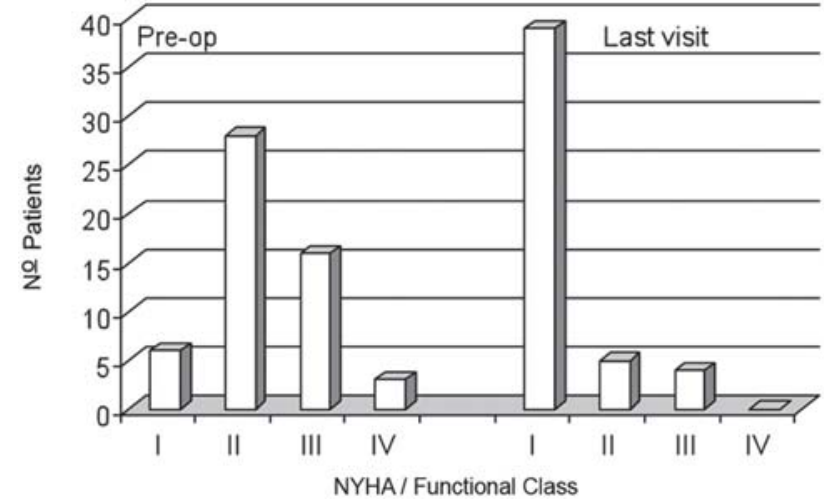

Fig. 5 - Symptoms related to aortic regurgitation before the surgery and their current situation

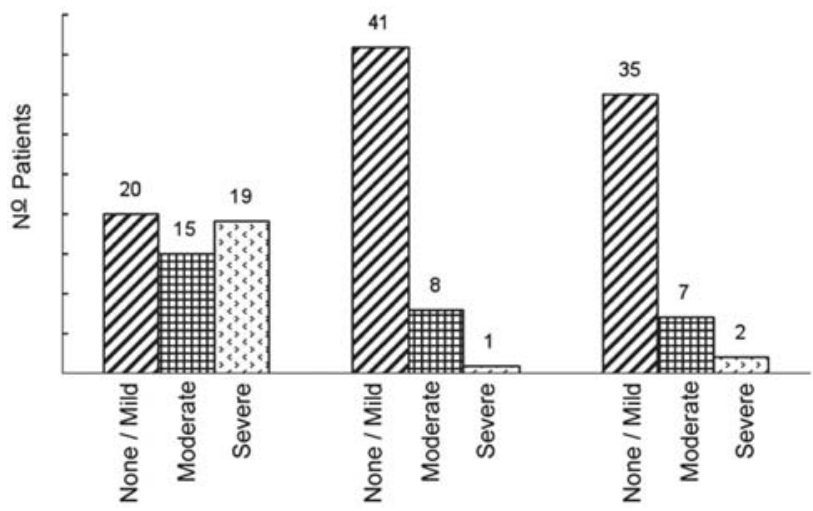

Fig. 6 - Grade of aortic valve preoperative regurgitation, in the early postoperative (from 6 months to 1 year), and in the last visit. Absolute number of patients provided

There was significant decreases of aortic regurgitation $(P<0.001)$, with $80 \%$ of the patients showing either mild aortic regurgitation or no regurgitation at all (Figure 6).

There were significant decreases of systolic and diastolic left ventricle diameters and volumes maintaining a normal ejection fraction.

\section{DISCUSSION}

Life expectancy following the aortic root surgery despite the surgical technique applied has shown to be similar to the expected survival curve of the general population [12]. The composite mechanical valve conduit choice implies in the need for life-long anticoagulation whereas the valvesparing surgery choice may raise questions regarding the longevity of the procedure.
Surgeries to correct aortic diseases performed in specialized centers with high surgical volume, present distinguished results with low operative mortality. In these centers, more demanding procedures must be encouraged in order to give the surgical community the best option for any specific operation.

The reduced number of aortic valve-sparing surgeries is attributed to the major complexity of the procedure, to the difficulty in reproducibility and to a higher risk of aortic regurgitation recurrence. In addition to be only considered by some as technically demanding, it is also an artistic procedure [13].

Some authors, from experimental studies, described the aortic root as a functional unit, associating the aortic ring's sigmoid shape, the intercomissural triangles and the sinuses of Valsalva [14]. The valve-sparing aortic root reconstruction surgery is frowned upon due to the difficulty in the reproduction of the perfect root geometry, without damage to either coronary flow or performance of the aortic leaflets thus avoiding traumatic wastage [15]. In the effort to reproduce this geometry, many valve-sparing reimplantation techniques have been proposed, including the use of the Valsalva graft. Nevertheless, despite the difficulty in obtaining the perfect reconstruction of the aortic root geometry, several groups, including ours, have achieved satisfactory results in the late evaluation of such surgeries [16-18].

Additional preoccupation exists when the valve-sparing operation is performed in Marfan's patients (1/3 of the patients of our study), because of the preservation of an altered structural leaflet (mutant fibrillin). In this study, only one Marfan's patient underwent aortic valve replacement probably due to an annular non-external fixation rather than a valve-related problem. It is important to point out that long-time follow-up with many patients is required to reach definitive conclusions. However, other series have already demonstrated similar results as those with patients both with and without this genetic alteration [19].

Schäfers et al. [7] suggested that the diameter in the base of the aortic ring must be one of the criteria to select the most appropriate valve-sparing technique. Through their study, they suggested that the remodeling technique should be used for smaller rings and the reimplantation technique for the dilated ones [20].

Reinforcing Schäfers's group’s idea, Hanke et al. [17] demonstrated that the recurrence of aortic regurgitation was related to three factors: Marfan's syndrome, the need for repair of one or more leaflets of the aortic valve and the diameter of the aortic ring. They showed that the remodeling technique for larger rings resulted in more regurgitation, while the reimplantation technique for smaller rings resulted in more leaflet deterioration. For these reasons, we started to analyze the aortic ring more carefully, which was not initially our target study. 
In view of the recurrence of aortic regurgitation in two of our patients who underwent remodeling valve-sparing surgery (5\%), due to annular dilation, an external fixation of the aortic ring is now routinely performed, as a technique complementation to the classic procedure proposed by Yacoub (Figure 1D).

However, the difference in long-term results concerning patients free from aortic valve reoperation can be attributed to an individualized technique chosen according to each patient's characteristics rather than a choice based entirely on the surgeon's preference for one technique over the other.

What most concerned us was the $20 \%$ of the patients, during follow-up, developed significant aortic regurgitation (16\% moderate and $4 \%$ severe). It is possible that part of these results may be attributed to the learning curve; to an inadequate technique chosen; to a high number of preoperative patients with important aortic regurgitation; and possibly to maintenance of previous damaged aortic leaflets.

This study has some limitations: (i) it is a transversal study with all difficulties of retrospective analyses; (ii) the reduced number of patients is an issue frequently associated with complex procedures and may raise difficulties to analyze comparative results; (iii) $60 \%$ of the patients' follow-up was shorter than 5 years and only $10 \%$ of the patients were evaluated in a 10 -year period; and (iv) even though the analysis shows a good performance of the valve-sparing technique, it does not reveal whether this procedure has better long-term results when compared to a mechanical valved conduit. Currently, we are analyzing data which may enable the comparison of both procedures.

Because of these results, we suggest that the valvesparing operation be performed by seasoned surgical groups in ascending aortic surgeries. The technique used (remodeling or reimplantation) must be chosen according to each patient's anatomic characteristics. In addition, specific care must be taken in order to avoid aortic regurgitation recurrence during follow-up, especially in patients with either Marfan's syndrome, or prolapsed valves which may need repair or dilated aortic rings.

\section{REFERENCES}

1. Lung B, Baron G, Butchart EG, Delahaye F, Gohlke-Bärwolf C, Levang OW, et al. A prospective survey of patients with valvular heart disease in Europe: the Euro Heart Survey on valvular heart disease. Eur Heart J. 2003;24(13):1231-43.
2. Kouchoukos NT, Marshall WG Jr, Wedige-Stecher TA. Eleven year experience with composite graft replacement of the ascending aorta and aortic valve. J Thorac Cardiovasc Surg. 1986;92(4):691-705.

3. Gott VL, Greene PS, Alejo DE, Cameron DE, Naftel DC, Miller DC, et al. Replacement of the aortic root in patients with Marfan's syndrome. N Engl J Med. 1999;340(17):1307-13.

4. Sarsam MA, Yacoub M. Remodeling of the aortic valve annulus. J Thorac Cardiovasc Surg. 1993;10(3):435-8.

5. David TE, Feindel CM. An aortic valve-sparing operation for patients with aortic incompetence and aneurysm of the ascending aorta. J Thorac Cardiovasc Surg. 1992;103(4):617-22.

6. Leyh RG, Schmidtke C, Sievers HH, Yacoub MH. Opening and closing characteristics of the aortic valve after different types of valve-preserving surgery. Circulation. 1999;100(21):2153-60.

7. Schäfers HJ, Fries R, Langer F, Nikoloudakis N, Graeter T, Grundmann U. Valve-preserving replacement of the ascending aorta: remodeling versus reimplantation. J Thorac Cardiovasc Surg. 1998;116(6):990-6.

8. David TE, Armstrong S, Ivanov J, Feindel CM, Omran A,Webb G. Results of aortic valve-sparing operations. J Thorac Cardiovasc Surg. 2001;122(1):39-46.

9. Yacoub MH, Gehle P, Chandrasekaran V, Birks EJ, Child A, Radley-Smith R. Late results of a valve-preserving operation in patients with aneurysms of the ascending aorta and root. J Thorac Cardiovasc Surg. 1998;115(5):1080-90.

10. Albes JM, Stock UA, Hartrumpf M. Restitution of the aortic valve: what is new, what is proven, and what is obsolete? Ann Thorac Surg. 2005;80(4):1540-9.

11. Edmunds Jr LH, Clark RE, Cohn LH, Grunkemeier GL, Miller DC, Weisel RD. Guidelines for reporting morbidity and mortality after cardiac valvular operations. The American Association for Thoracic Surgery, Ad Hoc Liaison Committee for Standardizing Definitions of Prosthetic Heart Valve Morbidity. Ann Thorac Surg. 1996;62(3):932-5.

12. Zehr KJ, Orszulak TA, Mullany CJ, Matloobi A, Daly RC, Dearani JA, et al. Surgery for aneurysms of the aortic root: a 30-year experience. Circulation. 2004;110(11):1364-71.

13. David TE. Aortic valve sparing operations. Ann Thorac Surg. 2002;73(4):1029-30.

14. El Khoury G, Glineur D, Rubay J, Verhelst R, d'Acoz Y, Poncelet A, et al. Functional classification of aortic root/valve abnormalities and their correlation with etiologies and surgical procedures. Curr Opin Cardiol. 2005;20(2):115-21. 
15. Cochran RP, Kunzelman KS, Eddy AC, Hofer BO, Verrier ED. Modified conduit preparation creates a pseudosinus in an aortic valve-sparing procedure for aneurysm of the ascending aorta. J Thorac Cardiovasc Surg. 1995;109(6):1049-58.

16. David TE, Ivanov J, Armstrong S, Feindel CM, Webb GD. Aortic valve-sparing operations in patients with aneurysms of the aortic root or ascending aorta. Ann Thorac Surg. 2002;74(5):S1758-61.

17. Hanke T, Charitos EI, Stierle U, Robinson D, Gorski A, Sievers $\mathrm{HH}$, et al. Factors associated with the development of aortic valve regurgitation over time after two different techniques of valve-sparing aortic root surgery. J Thorac Cardiovasc Surg. 2009;137(2):314-9.
18. Karck M, Kallenbach K, Hagl C, Rhein C, Leyh R, Haverich A. Aortic root surgery in Marfan syndrome: comparison of aortic valve-sparing reimplantation versus composite grafting. J Thorac Cardiovasc Surg. 2004;127(2):391-8.

19. Gott VL, Laschinger JC, Cameron DE, Dietz HC, Greene PS, Gillinov AM, et al. The Marfan syndrome and the cardiovascular surgeon. Eur J Cardiothorac Surg. 1996;10(3):149-58.

20. Langer F, Aicher D, Kissinger A, Wendler O, Lausberg H, Fries $\mathrm{R}$, et al. Aortic valve repair using a differentiated surgical strategy. Circulation. 2004;110(11 Suppl. 1):II67-73. 